\title{
Pembuatan Program Pengolahan Data GPS Analisa Pseudorange Dan Koreksi Troposfer
}

\author{
Mohammad Hadi Kunnuha dan Akbar Kurniawan \\ Departemen Teknik Geomatika, Fakultas Teknik Sipil dan Perencanaan, Institut Teknologi Sepuluh Nopember \\ (ITS) Surabaya \\ e-mail: akbar.geodesy@gmail.com
}

\begin{abstract}
Abstrak-Seiring berkembangnya jaman, muncul berbagai teknologi baru yang digunakan untuk memperoleh data lebih banyak dan cepat dalam penentuan posisi suatu objek, seperti perlengkapan global positioning system (GPS). Namun, tidak ada pengukuran yang tepat, setiap pengukuran terdapat kesalahan, nilai asli pengukuran tidak pernah diketahui, dan ukuran pasti kesalahan juga tidak diketahui. Dikarenakan kesalahan pada pengukuran, pengamatan secara berulang pada objek yang sama sering memberikan nilai yang berbeda. GPS (Global Positinoning System) merupakan sistem satelit yang digunakan untuk navigasi dan penentuan posisi. Pada dasarnya konsep dasar penentuan posisi dengan GPS adalah reseksi dengan jarak, yaitu dengan pengukuran jarak secara simultan ke beberapa satelit GPS. Meskipun sistem GPS memiliki banyak kelebihan, namun masih terdapat kendala dan keterbatasan dalam pemanfaatannya. Pemrosesan data GPS dan penganalisaan hasil bukan suatu hal yang mudah. Sehingga perlu adanya sebuah program yang dapat digunakan untuk menghitung posisi suatu objek dengan akurat. Salah satu bahasa pemrograman yang sering digunakan adalah $\mathrm{C}++$, sehingga program pengolahan data GPS ini menggunakan bahasa pemrograman terrsebut. Program yang telah dibuat merupakan program awal atau purwarupa untuk pengolahan data GPS. Program ini hanya digunakan untuk penentuan posisi GPS dengan metode absolut. Program ini menghasilkan nilai koordinat suatu titik yang diukur menggunakan satu receiver yang menangkap sinyal dari beberapa satelit. Dasil hasil perhitungan koordinat yang didapatkan pada program ini, didapatkan bahwa pada sinyal yang berbeda memberikan hasil koordinat yang berbeda. Pada sinyal C1 memberikan nilai koordinat titik dengan simpangan baku paling kecil dibandingkan sinyal P1 dan P2, yaitu sebesar 6,244 m tanpa koreksi troposfer dan 6,085 m dengan koreks troposfer. Koreksi troposfer juga mempengaruhi hasil yang didapatkan. Dengan adanya koreksi troposfer ini dapat menghilangkan kesalahan jarak yang menjadi lebih panjang karena sinyal GPS yang melewati lapisan troposfer. Dengan menggunakan koreksi troposfer, sinyal P2 memberikan hasil koordinat yang lebih presisi dengan nilai residu terhadap koordinat pendekatannya adalah sebesar 5,137 m.
\end{abstract}

Kata Kunci-GPS, Pemrograman, Pseudorange, Koreksi Troposfer.

\section{PENDAHULUAN}

$\mathrm{S}$ AAT ini manusia hidup di jaman informasi. Dengan adanya dukungan dari teknologi baru yang bermunculan, data dapat diperoleh dengan jumlah yang lebih banyak dari sebelumnya. Seperti pada survei lapangan, peralatan total station, perlengkapan global positioning system (GPS), kamera metrik dijital, dan sistem penginderaan jauh merupakan beberapa peralatan baru yang digunakan untuk memperoleh data dalam jumlah banyak dengan cepat. Salah satu aspek yang harus diperhatikan adalah pada semua pengukuran terdapat kesalahan. Dapat dinyatakan bahwa tidak ada pengukuran yang tepat, setiap pengukuran terdapat kesalahan, nilai asli pengukuran tidak pernah diketahui, dan ukuran pasti kesalahan juga tidak diketahui [1].

Dikarenakan kesalahan pada pengukuran, pengamatan secara berulang pada objek yang sama sering memberikan nilai yang berbeda. Perbedaan nilai yang sangat kecil pada beberapa pengukuran pada objek yang sama dipercaya dapat memberikan nilai kesalahan yang kecil. Namun pengukuran yang presisi tidak selalu memberikan nilai pengukuran yang mendekati nilai sesungguhnya. Dikarenakan kesalahan pada pengukuran, pengamatan secara berulang pada objek yang sama sering memberikan nilai yang berbeda. Perbedaan nilai yang sangat kecil pada beberapa pengukuran pada objek yang sama dipercaya dapat memberikan nilai kesalahan yang kecil, sehingga pengukuran tersebut dianggap presisi. Namun pengukuran yang presisi tidak selalu memberikan nilai pengukuran yang mendekati nilai sesungguhnya.

GPS (Global Positinoning System) merupakan sistem satelit yang digunakan untuk navigasi dan penentuan posisi yang dimiliki oleh Amerika Serikat. Pada dasarnya konsep dasar penentuan posisi dengan GPS adalah reseksi (pengikatan ke belakang) dengan jarak, yaitu dengan pengukuran jarak secara simultan ke beberapa satelit GPS [2]. GPS didesain untuk memberikan informasi posisi dan kecepatan tiga dimensi serta informasi waktu. Sistem GPS berjalan secara terus - menerus di seluruh dunia dan tidak terganggu oleh waktu dan cuaca. Sehingga GPS banyak dimanfaatkan terutama dalam bidang penetuan dan perubahan posisi [3]. Meskipun sistem GPS memiliki banyak kelebihan, namun masih terdapat kendala dan keterbatasan dalam pemanfaatannya. Pemrosesan data GPS dan penganalisaan hasil bukan suatu hal yang mudah. Dalam melakukan pemrosesan data untuk memperolah ketelitian posisi yang tinggi, digunakan konsep hitungan perataan kuadrat terkecil, statistika, serta perhitungan geodetik.

Oleh karena itu, muncul permasalahan terkait pemrosesan dan perhitungan data pengukuran GPS untuk memperoleh informasi koordinat suatu titik. Sehingga penelitian ini bertujuan untuk membuat sebuah program yang digunakan untuk mengolah data pengukuran GPS untuk mendapatkan posisi absolut dari data pseudorange $\mathrm{C} 1$, P1, dan P2. Adapun 
penelitian ini berfokus pada pembacaan data RINEX, perhitungan koordinat satelit, perhitungan koreksi troposfer, dan penggunaan data pseudorange untuk perhitungan koordinat titik receiver.

\section{METODOLOGI PENELITIAN}

\section{A. Data dan Peralatan}

\section{1) Data}

Data yang digunakan pada penelitian ini adalah data rinex navigasi dan rinex observasi hasil pengukuran GPS

2) Peralatan

Peralatan yang digunakan penelitian ini terbagi menjadi dua, yaitu sebagai berikut :

a. Perangkat keras

$$
\begin{array}{ll}
\text { - } & \text { Laptop } \\
\text { - } & \text { GPS Geodetik }
\end{array}
$$

b. Perangkat lunak

$$
\begin{array}{ll}
\text { - } \quad \text { Microsoft Office } 2013 \\
\text { - } \quad \text { Dev C++ }
\end{array}
$$

\section{B. Diagram Alir Penelitian}

Berikut adalah penjelasan diagram alir dari program seperti pada Gambar 1:

1. Membaca data RINEX

Program akan membuka data pesan navigasi satelit yang menyimpan informasi broadcast ephemeris yang terdiri dari parameter waktu, parameter orbit satelit dan parameter perturbasi orbit seperti pada tabel 1, yang akan digunakan untuk mengetahui koordinat satelit - satelit yang terhubung dengan receiver. Program juga akan membaca data observasi yang menyimpan informasi hasil pengamatan dari satelit ke pengamat. Informasi tersebut terdiri dari informasi waktu pengamatan, pseudorange,

\begin{tabular}{|c|c|}
\hline \multicolumn{2}{|c|}{ Parameter Waktu } \\
\hline$t_{\mathrm{oe}}$ & Waktu referensi parameter ephemeris (s) \\
\hline$t_{\mathrm{oc}}$ & Waktu referensi parameter jam (s) \\
\hline$a_{0}, a_{1}, a_{2}$ & $\begin{array}{l}\text { Koefisien polinomial untuk koreksi kesalahan jam } \\
\text { satelit, }\left(\mathrm{s}, \mathrm{s} / \mathrm{s} \text {, dan } \mathrm{s} / \mathrm{s}^{2}\right)\end{array}$ \\
\hline IOD & Issue of Data \\
\hline \multicolumn{2}{|c|}{ Parameter Orbit Satelit } \\
\hline$\sqrt{\mathrm{a}}$ & Akar dari sumbu panjang ellipsoid $\left(\mathrm{m}^{1 / 2}\right)$ \\
\hline $\mathrm{E}$ & Eksentrisitas \\
\hline$i_{o}$ & Inklinasi pada waktu $\mathrm{t}_{\mathrm{oe}}($ radian $)$ \\
\hline$\Omega_{0}$ & $\begin{array}{l}\text { Bujur dari titik naik (ascending node) pada waktu } t_{\mathrm{oe}} \\
\text { (radian) }\end{array}$ \\
\hline$\omega$ & Argumen perigee (radian) \\
\hline $\mathrm{M}_{\mathrm{o}}$ & Anomali menengah pada waktu $\mathrm{t}_{\mathrm{oe}}($ radian$)$ \\
\hline \multicolumn{2}{|c|}{ Parameter Perturbasi Orbit } \\
\hline$\Delta \mathrm{n}$ & $\begin{array}{l}\text { Perbedaan nilai mean motion dari nilai hitungannya } \\
\text { (radian) }\end{array}$ \\
\hline$\Omega$ & Kecepatan perubahan dari asensio rekta (radian/s) \\
\hline idot & Kecepatan perubahan dari inklinasi (radian/s) \\
\hline $\mathrm{C}_{\mathrm{us}}$ dan $\mathrm{C}_{\mathrm{uc}}$ & $\begin{array}{l}\text { Amplitudo dari suku - suku koreksi harmonik sinus } \\
\text { dan cosinus untuk argumen lintang (radian) }\end{array}$ \\
\hline $\mathrm{C}_{\mathrm{is}}$ dan $\mathrm{C}_{\mathrm{ic}}$ & $\begin{array}{l}\text { Amplitudo dari suku - suku koreksi harmonik sinus } \\
\text { dan cosinus untuk sudut iklinasi (radian) }\end{array}$ \\
\hline $\mathrm{C}_{\mathrm{rs}}$ dan $\mathrm{C}_{\mathrm{rc}}$ & $\begin{array}{l}\text { Amplitudo dari suku - suku koreksi harmonik sinus } \\
\text { dan cosinus untuk radius orbit }(\mathrm{m})\end{array}$ \\
\hline
\end{tabular}
fase, dan frekuensi doppler.

Tabel 1.

Informasi Broadcast Ephemeris

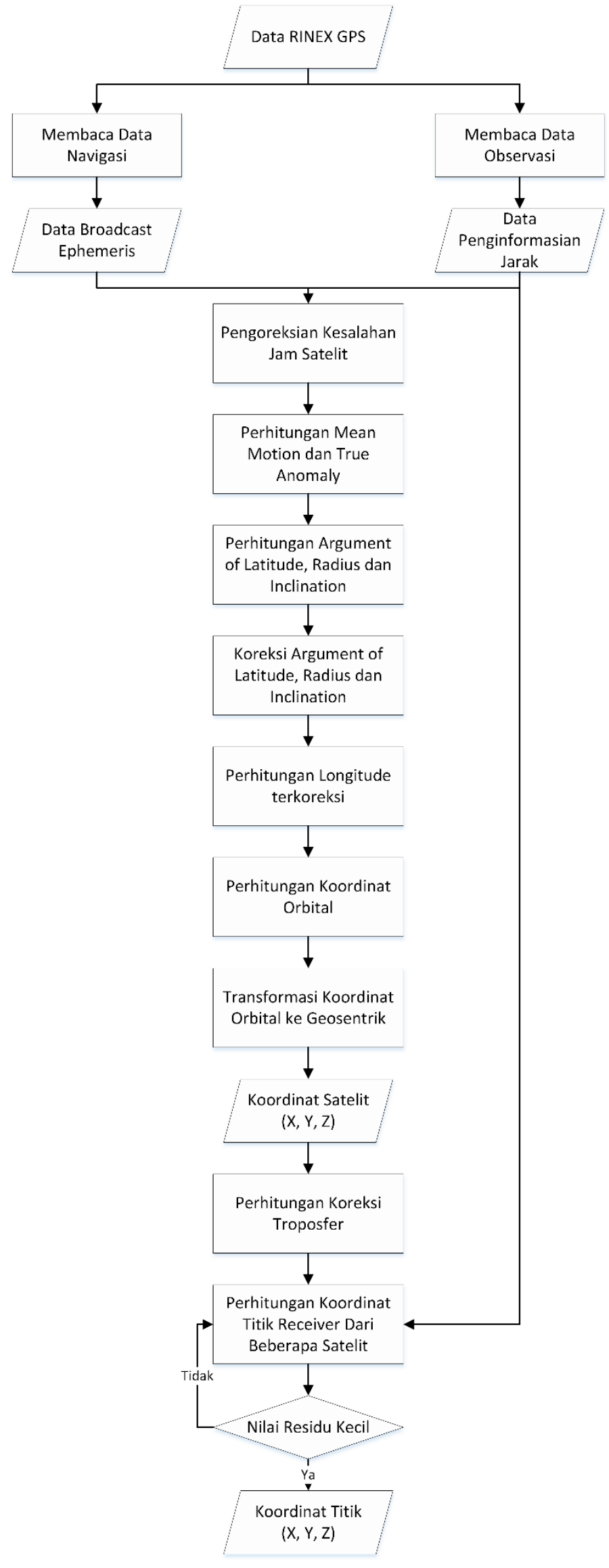

Gambar 1. Diagram Tahap Pengolahan Data 
2. Perhitungan koordinat satelit

Selanjutnya program akan melakukan perhitungan koordinat satelit berdasarkan data broadcast ephemeris yang telah didapatkan. Adapun tahap - tahap perhitungan koordinat satelit adalah sebagai berikut :

a. Menghitung Julian Date dari epok yang akan ditentukan nilai koordinatnya

$J D$

$=$ floor $(365.25 x$ Year $)$

$+($ floor $(30.6001 x($ Month +1$))$

+ Day + $(U T / 24)+1720981.5$

b. Menghitung Week dan Second of Week dari data epok

$e=$ floor $\left(\frac{\text { floor }(J D+0.5)+1537-122.1}{365.25}\right)$

$f=$ floor $\left(\frac{\text { floor }(J D+0.5)+1537-e}{30.6001}\right)$

$d=\left(\frac{\text { floor }(J D+0.5)+1537-e}{365.25}\right)$

Day of Week $=\operatorname{Rem}($ floor $(J D+0.5), 7)$

Week $=$ floor $\left(\frac{J D-2444244.5}{7}\right)$

$T_{r x}=\operatorname{Rem}((d+$ Day of Week +1$), 86400)$

c. Menghitung koreksi waktu dari epok terhadap kesalahan jam satelit. Koreksi waktu ini diperlukan karena meskipun semua satelit memiliki sistem jam atom, akan tetapi memiliki kekurangan dalam hal sinkronisasi antara broadcast sinyal satelit dan sistem waktu GPS [4].

$T_{s}=T_{r x}-(P / c)$

$d t=T_{s}-T_{o c}$

$\varepsilon^{s c}=a_{0}+a_{1} x d t+a_{2} x d t^{2}$

$T_{G P S}=T_{S}-\varepsilon^{s c}$

$T_{K}=T_{G P S}-T_{o e}$

d. Menghitung nilai Mean Motion yang telah terkoreksi $\mathrm{n}=$ no $+\Delta \mathrm{n}$

e. Menghitung nilai Mean Anomaly

$\mathrm{Mk}=\mathrm{Mo}+\mathrm{n} \cdot \mathrm{tk}$

f. Menghitung nilai True Anomaly $\cos \vartheta \mathrm{k}=(\cos E \mathrm{k}-\mathrm{e}) /(1-\mathrm{e} \cdot \cos \mathrm{Ek})$

$\sin \vartheta_{k}=\sqrt{ }\left(1-e^{2}\right) \cdot \sin E_{k} /\left(1-e \cdot \cos E_{k}\right)$

g. Menghitung nilai Argument of Latitude $\varphi \mathrm{k}=\vartheta \mathrm{k}+\omega$

h. Menghitung koreksi Argument of Latitude $\delta \mathrm{uk}=$ Cuc. $\cos 2 \varphi \mathrm{k}+$ Cus. $\sin 2 \varphi \mathrm{k}$

i. Menghitung koreksi Radius $\delta \mathrm{rk}=$ Crc. $\cos 2 \varphi \mathrm{k}+$ Crs. $\sin 2 \varphi \mathrm{k}$

j. Menghitung koreksi Inclination $\delta \mathrm{ik}=$ Cic. $\cos 2 \varphi \mathrm{k}+$ Cis. $\sin 2 \varphi \mathrm{k}$

k. Menghitung Argument of Latitude terkoreksi $\mathrm{uk}=\varphi \mathrm{k}+\delta \mathrm{uk}$

1. Menghitung Radius terkoreksi $\mathrm{rk}=\mathrm{a} \cdot(1-\mathrm{e} \cdot \cos \mathrm{Ek})+\delta \mathrm{rk}$

m. Menghitung Inclination terkoreksi $\mathrm{ik}=$ io + idot. $\mathrm{tk}+\delta \mathrm{ik}$

n. Menghitung nilai Longitude terkoreksi
$\Omega \mathrm{k}=\Omega \mathrm{o}+\left(' \Omega-{ }^{\prime} \Omega \mathrm{e}\right) \mathrm{tk}-{ }^{\prime} \Omega \mathrm{e}$ toe

o. Menghitung koordinat satelit di bidang orbit

$\mathrm{xk}=\mathrm{rk} \cdot \cos \mathrm{uk}$

$\mathrm{yk}=\mathrm{rk} \cdot \sin \mathrm{uk}$

p. Menghitung koordinat satelit dalam bidang geosentrik $\mathrm{Xk}=\mathrm{xk} \cdot \cos \Omega \mathrm{k}-$ yk. $\cos \mathrm{ik} \cdot \sin \Omega \mathrm{k}$

$\mathrm{Yk}=\mathrm{xk} \cdot \sin \Omega \mathrm{k}+\mathrm{yk} \cdot \cos \mathrm{ik} \cdot \cos \Omega \mathrm{k}$

$\mathrm{Zk}=\mathrm{yk} \cdot \sin \mathrm{ik}$

3. Perhitungan koreksi troposfer

Bias troposfer dihitung menggunakan model Saastomeinen, dimana $\mathrm{p}$ adalah tekanan atmosfer, $\mathrm{T}$ adalah temperatur, e adalah tekanan parsial dari uap air, dan $\mathrm{z}$ adalah sudut zenith ke satelit yang diamati.

$d_{\text {trop }}=\frac{0.002277}{\cos z}\left\{p+\left(\frac{1255}{T}+0.05\right) e-\tan ^{2} z\right\}$

4. Perhitungan koordinat receiver

Pada penentuan koordinat kartesian 3D dari suatu pengamat $\left(\mathrm{X}_{\mathrm{p}}, \mathrm{Y}_{\mathrm{p}}, \mathrm{Z}_{\mathrm{p}}\right)$ dengan menggunakan metode penentuan posisi absolut, pengamat pada dasarnya mengukur jarak $(\rho)$ ke beberapa satelit yang sudah diketahui koordinatnya $\left(\mathrm{X}_{\mathrm{i}}, \mathrm{Y}_{\mathrm{i}}, \mathrm{Z}_{\mathrm{i}}\right)$. Maka ada empat persamaan yang disusun untuk pengamatan jarak ke empat satelit GPS, yaitu :

$$
\begin{aligned}
& \sqrt{\left(X_{p}-X_{k 1}\right)^{2}+\left(Y_{p}-Y_{k 1}\right)^{2}+\left(Z_{p}-Z_{k 1}\right)^{2}}+c . d t=\rho_{1} \\
& \sqrt{\left(X_{p}-X_{k}\right)^{2}+\left(Y_{p}-Y_{k 2}\right)^{2}+\left(Z_{p}-Z_{k 2}\right)^{2}}+c . d t=\rho_{2} \\
& \sqrt{\left(X_{p}-X_{k 3}\right)^{2}+\left(Y_{p}-Y_{k 3}\right)^{2}+\left(Z_{p}-Z_{k 3}\right)^{2}}+c . d t=\rho_{3} \\
& \sqrt{\left(X_{p}-X_{k 4}\right)^{2}+\left(Y_{p}-Y_{k 4}\right)^{2}+\left(Z_{p}-Z_{k 4}\right)^{2}}+c . d t=\rho_{4}
\end{aligned}
$$

dimana $\mathrm{c}$ adalah kecepatan cahaya dan dt adalah kesalahan dan offset dari jam receiver.

Pada persamaan di atas, ada empat parameter yang harus ditentukan/diestimasi yaitu :

- koordinat pengamat $\left(\mathrm{X}_{\mathrm{P}}, \mathrm{Y}_{\mathrm{P}}, \mathrm{Z}_{\mathrm{P}}\right)$, dan

- kesalahan dan offset dari jam receiver GPS (dt).

Oleh sebab itu, untuk penentuan posisi 3D pada satu epok dengan menggunakan data pseudorange diperlukan minimal pengamatan ke empat buah satelit GPS.

\section{HASIL DAN ANALISA}

\section{A. Tampilan Program Saat Dijalankan}

Program pengolahan data pengukuran GPS yang telah dibuat menggunakan bahasa pemrograman $\mathrm{C}++$ dapat dilihat seperti pada Gambar 2. Program ini digunakan untuk menentukan posisi suatu titik yang diamati dengan metode absolut. Pada program tersebut ditunjukkan nama dari data RINEX navigasi dan observasi yang dibaca. Program menunjukkan jumlah data informasi orbit satelit yang tersimpan pada data navigasi, serta jumlah epok data pengamatan yang tersimpan pada data observasi. Setelah program selesai membaca data navigasi dan observasi, program tersebut akan menunjukkan hasil perhitungan koordinat titik yang diamati. Hasil koordinat titik pengamatan ditunjukkan dalam sistem koordinat kartesian geosentrik dan sistem koordinat geografis serta tingginya. Juga 
ditampilkan nilai simpangan baku dari hasil perhitungan koordinat titik pengamatan.

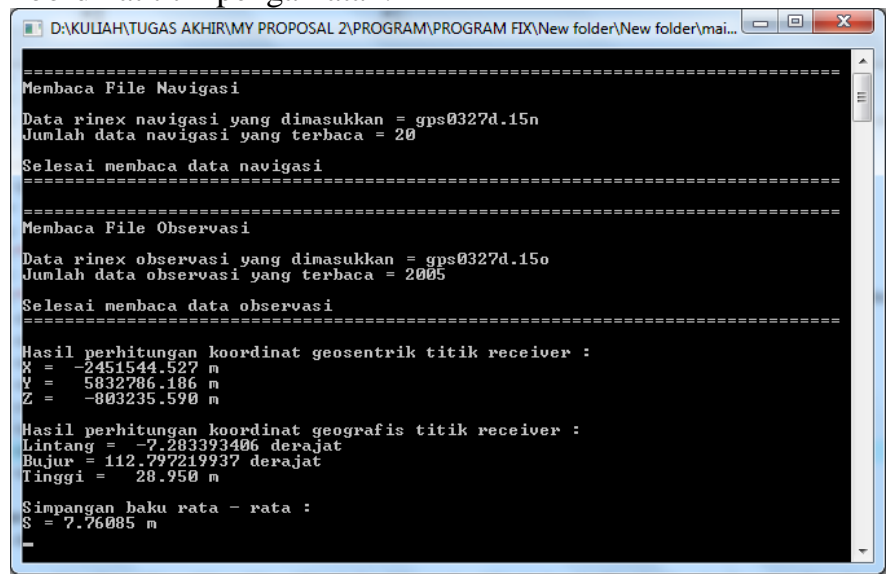

Gambar 2. Program Pengolahan Data GPS

\section{B. Hasil Pengolahan Data GPS tanpa Koreksi Troposfer}

Pada percobaan program pertama, dilakukan perhitungan koordinat titik pengamatan dari beberapa satelit. Perhitungan koordinat titik ini dilakukan tanpa menggunakan koreksi troposfer. Perhitungan koordinat titik juga dilakukan dengan menggunakan kode sinyal penginformasian jarak yang berbeda, yaitu C1, P1, dan P2. Hasil perhitungan koordinat titik dapat dilihat pada Tabel 2 berikut. Pada sinyal C1 memberikan nilai simpangan baku (S) paling kecil dan sinyal P2 memberikan nilai simpangan baku paling besar.

Tabel 2.

Hasil Koordinat Tanpa Koreksi Troposfer

\begin{tabular}{lllll}
\hline \hline Sinyal & $\mathrm{X}(\mathrm{m})$ & $\mathrm{Y}(\mathrm{m})$ & $\mathrm{Z}(\mathrm{m})$ & $\mathrm{S}(\mathrm{m})$ \\
$\mathrm{C} 1$ & -2451553.250 & 5832811.347 & -803240.663 & 6.244 \\
P1 & -2451552.831 & 5832811.292 & -803240.537 & 6.732 \\
P2 & -2451555.624 & 5832819.817 & -803241.757 & 8.232 \\
\hline \hline
\end{tabular}

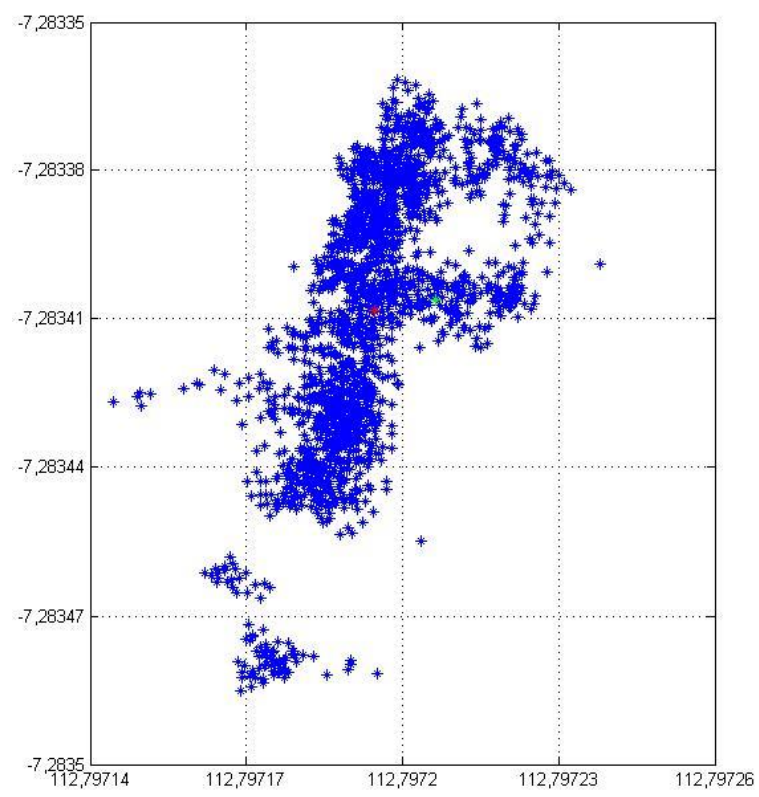

Gambar 3. Sebaran Koordinat Titik Per Epok Tanpa Koreksi Troposfer

Nilai koordinat titik tersebut merupakan nilai rata - rata dari nilai koordinat titik pada tiap epok pengamatan. Pada setiap epok dilakukan perhitungan koordinat titik pengamatan dari data pseudorange beberapa satelit yang terhubung disetiap epoknya. Data - data koordinat pada tiap epok tersebut selanjutnya dijumlahkan kemudian dirata - rata sehingga mendapatkan nilai koordinat seperti pada Tabel 2. Sebaran nilai koordinat titik pada tiap epok tersebut dapat dilihat pada Gambar 3.

Akan tetapi perbedaan nilai koordinat titik hasil perhitungan dengan koordinat pendekatan yang terdapat pada data RINEX memberikan nilai residu yang besar seperti pada Tabel 3. Nilai koordinat pendekatan yang terdapat pada data RINEX adalah $X$ $=-2451544.884 \mathrm{~m}, \mathrm{Y}=5832790.906 \mathrm{~m}$, dan $\mathrm{Z}=-803237.586$ m. Pada sinyal P2 memberikan nilai residu paling besar dan sinyal P1 memberikan nilai residu paling kecil.

Tabel 3.

Beda Nilai Dengan Koordinat Pendekatan

\begin{tabular}{lllll}
\hline Sinyal & $\mathrm{dX}(\mathrm{m})$ & $\mathrm{dY}(\mathrm{m})$ & $\mathrm{dZ}(\mathrm{m})$ & RMSE $(\mathrm{m})$ \\
\hline C1 & 8.556 & -18.933 & 3.214 & 22.345 \\
P1 & 8.137 & -18.878 & 3.088 & 21.446 \\
P2 & 10.930 & -27.403 & 4.308 & 30.314 \\
\hline \hline
\end{tabular}

\section{Hasil Pengolahan Data GPS dengan Koreksi Troposfer}

Pada percobaan program kedua, perhitungan koordinat titik ini dilakukan dengan menambahkan koreksi troposfer. Hasil perhitungan koordinat titik yang telah ditambahkan koreksi troposfer dapat dilihat pada Tabel 4 berikut. Pada sinyal C1 memberikan nilai simpangan baku paling kecil dan sinyal P2 memberikan nilai simpangan baku paling besar.

Tabel 4

Hasil Koordinat Dengan Koreksi Troposfer

\begin{tabular}{lllll}
\hline \hline Sinyal & $\mathrm{X}(\mathrm{m})$ & $\mathrm{Y}(\mathrm{m})$ & $\mathrm{Z}(\mathrm{m})$ & $\mathrm{S}(\mathrm{m})$ \\
\hline C1 & -2451541.254 & 5832776.738 & -803234.556 & 6.085 \\
P1 & -2451541.733 & 5832777.660 & -803234.370 & 6.414 \\
P2 & -2451544.527 & 5832786.186 & -803235.590 & 7.761 \\
\hline \hline
\end{tabular}

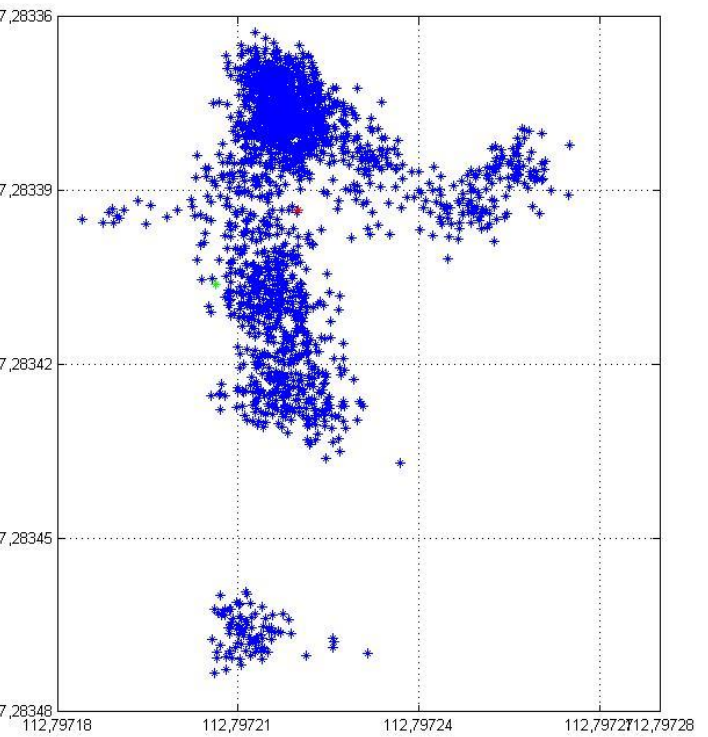

Gambar 4. Sebaran Koordinat Titik Per Epok Dengan Koreksi Troposfer

Pada perhitungan koordinat titik dengan menggunakan koreksi troposfer, diperoleh sebaran nilai koordinat titik pada tiap epok seperti pada Gambar 4. Pada Gambar 4 tersebut, 
rentang nilai pada sumbu $\mathrm{X}$ dan $\mathrm{Y}$ lebih kecil dibandingkan dengan rentang nilai pada Gambar 3. Rentang nilai yang lebih kecil tersebut menunjukkan bahwa hasil perhitungan koordinat dengan menggunakan koreksi troposfer lebih presisi dibandingkan dengan nilai koordinat tanpa menggunakan koreksi troposfer.

Namun perbedaan nilai koordinat titik hasil perhitungan dengn koordinat pendekatan yang terdapat pada data RINEX memberikan nilai yang lebih kecil dibandingkan dengan hasil yang tidak menggunakan koreksi troposfer seperti pada Tabel 5. Pada sinyal P2 memberikan nilai residu paling kecil dan sinyal C1 memberikan nilai residu paling besar. Koreksi troposfer ini dilakukan untuk menghilangkan efek lapisan troposfer yang mempengaruhi kecepatan sinyal GPS sehingga hasil pengukuran jarak dari satelit ke receiver menjadi lebih panjang, seperti pada Tabel 3 yang memiliki nilai residu lebih besar dibandingkan pada Tabel 5 .

Dengan nilai residu dan simpangan baku yang besar tersebut, metode penentuan posisi absolut ini lebih sesuai digunakan untuk keperluan navigasi dan tidak cocok untuk penetuan posisi yang akurat.

Tabel 5 .

Beda Nilai Dengan Koordinat Pendekatan

\begin{tabular}{|c|c|c|c|c|}
\hline Sinyal & dX (m) & dY (m) & $\overline{d Z(m)}$ & RMSE (m) \\
\hline $\mathrm{C} 1$ & -3.440 & 15.676 & -2.893 & 20.019 \\
\hline P1 & -2.961 & 14.754 & -3.079 & 18.663 \\
\hline P2 & -0.167 & 6.228 & -1.859 & 12.292 \\
\hline
\end{tabular}

\section{Hasil Pengolahan Data Pengukuran Beda Waktu}

Pada pengolahan data pengukuran pada titik yang sama yang diamati pada waktu yang berbeda, diperoleh hasil koordinat titik pengamatan dengan menggunakan kode $\mathrm{P} 2$ seperti pada Tabel 6 berikut. Hasil perhitungan koordinat titik yang diamati pada waktu yang berbeda tersebut memiliki perbedaan nilai yang kecil. Beda nilai koordinat X sebesar 1,179 m; Y sebesar $0,112 \mathrm{~m}$; dan Z sebesar $0,102 \mathrm{~m}$. Sehingga memiliki nilai residu sebesar $1,189 \mathrm{~m}$.

Tabel 6.

Nilai Koordinat Pengukuran Beda Waktu

\begin{tabular}{llll}
\hline \hline Tanggal & $\mathrm{X}(\mathrm{m})$ & $\mathrm{Y}(\mathrm{m})$ & $\mathrm{Z}(\mathrm{m})$ \\
\hline 4 Januari 2016 & -2426318.592 & 5838209.248 & -846360.488 \\
5 Januari 2016 & -2426319.771 & 5838209.136 & -846360.590 \\
\hline \hline
\end{tabular}

\section{KESIMPULAN DAN SARAN}

Adapun hal-hal yang dapat disimpulkan dari penelitian ini adalah:

1. Nilai koordinat titik receiver yang diperolah dari data pseudorange/jarak yang didapatkan dari sinyal $\mathrm{C} 1$ memberikan nilai simpangan baku paling kecil, sedangkan sinyal P2 memberikan nilai simpangan baku paling besar.

2. Nilai koordinat titik receiver yang menggunakan koreksi troposfer memberikan hasil yang lebih mendekati dengan koordinat pendekatan yang terdapat pada data RINEX observasi karena menghilangkan efek lapisan troposfer yang menyebakan jarak antara satelit dan receiver lebih panjang.

3. Koordinat titik yang didapatkan dari sinyal P2 memberikan nilai residu paling kecil terhadap koordinat pendekatan saat menggunakan koreksi troposfer, namun memberikan nilai residu paling besar saat tidak menggunakan koreksi troposfer.

4. Pengolahan data pengukuran GPS pada titik yang sama yang diamati pada waktu yang berbeda memberikan hasil nilai koordinat yang hampir sama dengan nilai residunya sebesar $1,189 \mathrm{~m}$.

Adapun saran yang dapat diberikan pada penelitian ini adalah sebagai berikut:

1. Perlu adanya pengembangan lanjut pada program agar metode penentuan posisi yang digunakan lebih beragam.

2. Perlu adanya penambahan beberapa macam koreksi pada algoritma perhitungan posisi titik receiver agar hasil yang didapatkan dapat lebih akurat.

3. Diharapkan program dapat dikembangkan dengan menggunakan Graphic User Interface (GUI) agar lebih mudah digunakan oleh pemakai.

\section{DAFTAR PUSTAKA}

[1] P. R. Ghilani, C. D. \& Wolf, Adjustment Computation : Spatial Data Analysis. New Jersey: John Wiley And Sons, 2006.

[2] J. Abidin, H. Z., Jones, A. \& Kahar, Survei Dengan GPS. Jakarta: Pradnya Paramita, 2002.

[3] H. . Abidin, Survei dengan GPS. Jakarta: Pradnya Paramita, 2002.

[4] S. Bidikar, B., Rao, G.S., Ganesh, L. \& Kumar, Satellite Clock Error and Orbital Solution Error Estimation for Precise Navigations Applications. 2014. 